\title{
Douglas Kellner: a retomada da teoria crítica frankfurtiana sob o impacto da leitura de Marcuse
}

\section{Otávio Daros}

Graduado em Jornalismo pela Pontifícia Universidade Católica do Rio Grande do Sul (PUCRS). Mestrando em Comunicação Social pela mesma instituição. Tem experiência profissional no portal de notícias G1.

E-mail: otavio.daros@gmail.com
Resumo: Este trabalho apresenta uma revisão da teoria crítica, checando as contribuições e as limitações da obra dos teóricos da primeira geração da Escola de Frankfurt, a partir da literatura fornecida pelo pesquisador norte-americano Douglas Kellner. O autor é compreendido como um teorizador do capitalismo avançado, que se apoia na tradição crítica - em especial na obra de Herbert Marcuse -, e por essa via começa a ver a relevância da cultura e dos meios de comunicação no contexto contemporâneo.

Palavras-chave: Douglas Kellner; Teoria crítica; Herbert Marcuse.

Douglas Kellner: the resumption of Frankfurt's critical theory under the impact of Marcuses' reading

Abstract: This study presents a review of critical theory, looking at the contributions and limitations of the work of the first-generation theorists of the Frankfurt School, based on the literature provided by the American researcher Douglas Kellner. The author is understood as a theorist of advanced capitalism, based on the critical tradition - especially in the work of Herbert Marcuse -, who begins to see the relevance of culture and the media in the contemporary context.

Keywords: Douglas Kellner; Critical theory; Herbert Marcuse. 


\section{A formação de Kellner}

Constatamos ao analisar alguns dos primeiros escritos publicados por Douglas Kellner, durante os anos de 1980, que seu pensamento é edificado sobre o estudo do marxismo, apoiado na tradição crítica desenvolvida por Horkheimer, Adorno, Benjamin, Marcuse e Habermas, entre outros. No trânsito dessas vertentes, Kellner se interessa por mostrar como as tecnologias modernas, em especial os meios de comunicação, interferem e geram novos modos de cultura e sociedade. Assim, podemos situá-lo, sobretudo, como um teorizador do capitalismo avançado.

Em 1968, quando estudou filosofia na Universidade de Columbia, Kellner inclinou-se, à primeira vista, para a fenomenologia e para o existencialismo. Foi inspirado pela onda de manifestações estudantis da época, entrando para a luta da reforma educacional e para os movimentos contrários à Guerra do Vietnã. A relação de Kellner com a New Left é influenciada fortemente pelo ativismo político de Marcuse.

Para ajudar a entender esses eventos, eu li as obras de Herbert Marcuse, na época da publicação de "An Essay on Liberation" (1969). Eu melhor compreendi os escritos de Marcuse e os fundamentos filosóficos do movimento estudantil para o qual eu estava cada vez mais atraído. (KELLNER, 1999b: 1)

No ano seguinte, recebeu uma bolsa de estudos e mudou-se para a Alemanha com o objetivo de desenvolver sua dissertação sobre Martin Heidegger (Heidegger's Concept of Authenticity, 1973). Junto à pesquisa, dedicou-se ao estudo da Dialética do esclarecimento de Adorno e Horkheimer, acompanhado dos escritos marxistas de Karl Korsch e György Lukács. Naquele período, assinala também a importância da descoberta do texto adorniano $O$ jargão da autenticidade (1964).

No começo de 1970, morou em Paris, onde estudou filosofia francesa. Teve a oportunidade de assistir às aulas de Claude Lévi-Strauss, Foucault, Deleuze e Lyotard, além de acompanhar os trabalhos de Baudrillard e Derrida.

Ao voltar para os Estados Unidos, em 1972, concluiu seu trabalho sobre Heidegger. Logo depois, tornou-se professor na Universidade do Texas em Austin, onde lecionou por mais de duas décadas. Observamos que o período guarda uma alternância no caminho teórico que será percorrido pelo autor até a atualidade. Deixando os estudos heideggerianos de lado, Kellner se concentra na compreensão e na análise dos processos sociais existentes no sistema tecnocapitalista, explorando o marxismo e a teoria crítica. $O$ tecnocapitalismo trata da configuração da sociedade capitalista em que o conhecimento técnico-científico e a tecnologia de ponta transformam os processos de produção, gerando uma nova organização social e formas de cultura, nas palavras do próprio Kellner (1989).

Em 1997, Kellner passa a ocupar a cadeira de George F. Kneller em Filosofia da Educação, na Universidade da Califórnia. A troca de instituição não foi por acaso, ela esconde momentos obscuros enfrentados pelo corpo docente da Universidade do Texas, estado que era governado por George W. Bush desde 1995. As publicações lançadas por Kellner naquela década trabalhavam temas, como a crise democrática enfrentada pela televisão, que eram manipulados pela pressão econômica e pelas políticas do governo e das corporações.

Ele vinha se dedicando, de modo geral, ao estudo da dinâmica dualista do capitalismo avançado e observou que o tecnocapitalismo abriga, ao mesmo tempo, formas de progresso e de dominação.

Durante a década de 1950, os teóricos de várias tradições começaram a discutir uma "segunda revolução industrial" caracterizada por novos tipos de produção, novas fontes de energia e novas tecnologias. Considerando que a primeira revolução industrial caracterizou-se pela fabricação em que as máquinas substituíram as mãos, e em que a mecanização substituiu o trabalho manual, na segunda revolução industrial as máquinas e as novas tecnologias substituíram os 
cérebros e desempenharam um papel importante na reestruturação do processo trabalhista e outros domínios da vida social. (Id., 1989: 179)

Evidenciamos, de maneira direta, a inspiração de Kellner pelas ideias de Marcuse. Na sua leitura, o capitalismo avançado, tratado por Marcuse, não é em sua totalidade repressivo: inclusive pode adquirir caráter progressista, na medida em que fornece condições para a produção de "novas tecnologias e modos de informação, que têm um impacto potencialmente benéfico na vida humana" (Ibid.: 182). Entre eles, estão: "maior diversidade de escolha, maior possibilidade de autonomia cultural e maiores aberturas para as intervenções de outras culturas e ideias" (Id., 2001: 26).

No entanto, como o próprio autor reconhece, não é o que se vê ao analisar a modernidade. As novas tecnologias não foram e não estão sendo usadas para beneficiar unicamente a humanidade, mas, sim, em muitas das vezes, encontram-se a favor da "contínua imposição da mercantilização e do trabalho assalariado, que exacerba as desigualdades de classe" (Id., 1989: 182). Assim como "propiciam poderosas formas de controle social por meio de técnicas de doutrinação e manipulação mais eficientes, sutis e ocultas" (Id., 2001: 26).

\section{Teoria crítica e apropriação de Marcuse}

No exame empreendido por Kellner acerca da tradição crítica, em especial do trabalho de Marcuse, entendemos que a tecnologia opera pelo imperativo da lógica capitalista, que serve, em última instância, ao lucro e, mais recentemente, à dominação das corporações.

Em outras palavras, sob o tecnocapitalismo, como máquinas, automação de produção, novas tecnologias e informatização, substituem a força de trabalho humana, tanto manual quanto mental, a fonte do excedente muda de extração de humanos para extração de máquinas e a acumulação é alimentada por Desenvolvimento tecnológico e automação, e não apenas pela organização mais eficiente da força de trabalho humana, como na era da gestão científica e do taylorismo. (Id., 1989: 179)

Kellner destaca que Marcuse percebeu as "tendências destrutivas nas realizações mais célebres do capitalismo avançado", esclarecendo que o crescimento da sociedade é "baseado no desperdício e na destruição, e seu progresso é alimentado pela exploração e repressão" (Id., 1984: 241).

Para além de abstrações, a identificação de Kellner com Marcuse ocorre também na esfera política. "Pelo menos algumas versões da teoria crítica são motivadas por um interesse em relacionar a teoria à política, e um interesse na emancipação daqueles que são oprimidos e dominados" (Id., 1989: 2), distinguindo indiretamente Marcuse de outros colegas da Escola de Frankfurt. Marcuse teve a capacidade de construir uma trajetória política e intelectual, fundindo sua filosofia a uma postura política radical.

Kellner (1984: 5) acentua que, após a Segunda Guerra, "Marcuse criticou duramente tanto o marxismo soviético quanto o capitalismo norte-americano, chamando a atenção para novas formas de dominação, repressão e controle social nas sociedades industriais avançadas". E argumenta que foram as "tentativas heroicas e muitas vezes desesperadas de reconstruir a teoria marxista, e criticar suas limitações e deficiências" (Ibid.) que distinguiam Marcuse.

Marcuse defendia geralmente a ala mais radical do movimento estudantil, enquanto Habermas criticava alguns dos seus excessos, mesmo defendendo muitos de seus objetivos e posições. Horkheimer atacou radicalmente os estudantes radicais, e enquanto Adorno às vezes apoiava suas causas, ele também se distanciou da nova esquerda alemã. (Id., 1989: 205) 
Marcuse atuou junto a esses pensadores no Instituto de Pesquisa Social: o primeiro centro de pesquisa com orientação marxista aberto na Alemanha, responsável pela tradição crítica. O "termo teoria crítica foi cunhado pela primeira vez em 1937, depois que a maioria dos membros do Instituto já havia emigrado para os Estados Unidos" (Id., 1990: 8), em razão do triunfo de Hitler.

Esse coletivo intelectual é chamado por muitos de Escola de Frankfurt. Mas Kellner (1989: 2) refuta o termo, uma vez que o considera "enganoso, porque grande parte do trabalho mais importante do grupo foi feito no exílio nos Estados Unidos". O autor argumenta que Marcuse, por exemplo, "nunca trabalhou, de fato, com o Instituto em Frankfurt" (Id., 1984: 92), já que antes de os nazistas chegarem ao poder, ele já residia e trabalhava em Genebra. Porém, em seus livros e artigos posteriores a Critical theory, marxism, and modernity (1989), Kellner emprega a expressão Escola de Frankfurt para designar a corrente crítica, como sinônimo.

Kellner (1989: 7) sugere que os estudiosos não devem compreender a teoria crítica como unidade, e sim como uma série de "características que a definem em termos de método, pressupostos e posições". A tradição crítica, por essência, é uma negação da "divisão acadêmica arbitrária ou convencional" (Ibid.). A formação e atuação dos teóricos críticos pode ser interpretada como contraponto à crescente especialização do conhecimento, que cada vez menos busca dialogar com outros campos do saber, caminhando para a simplificação em vez da complexidade.

Kellner observa que a tendência de especialização dos campos de conhecimento surge a partir da Segunda Guerra. E que até hoje tem como consequência divisões acadêmicas. A comunicação torna-se um exemplo, quando é separada dos estudos da cultura.

Contrária ao afastamento entre os campos do saber, a tradição crítica possui o mérito atravessar e debilitar "fronteiras entre disciplinas concorrentes e sublinhar as interconexões entre filosofia, economia e política, cultura e sociedade" (Ibid.). O corpo de colaboradores do Instituto é uma prova disso:

Especialistas em filosofia e teoria social como Horkheimer e Marcuse escreveram artigos sobre filosofia e história intelectual; Fromm esboçou uma psicologia socialista materialista; Leo Lowenthal e Walter Benjamin desenvolveram abordagens para uma sociologia da literatura, enquanto Adorno contribuiu para o desenvolvimento de uma sociologia da música popular e levou a cabo críticas ideológicas de certos modos dominantes de pensamento; Pollock, Grossmann e outros contribuíram com artigos sobre economia política, enquanto Franz Neuman, Otto Kirchheimer e outros contribuíram com artigos sobre sociologia política. (Ibid.: 26)

Kellner identifica que a teoria crítica seguiu, além de Marx, orientações de Friedrich Nietzsche, Max Weber e Sigmund Freud. Para o autor, o potencial da corrente está na preocupação com o "destino da modernidade" e no fornecimento de teorias sistemáticas e abrangentes da sociedade moderna "combinadas com diagnósticos críticos das suas limitações, patologias e efeitos destrutivos", gerando elementos para uma defesa progressista (Ibid.: 3).

De acordo com ele, uma das principais contribuições da teoria crítica é justamente a "apropriação da herança dialética hegeliana-marxista, que vê categorias e análises socialmente críticas [...] e necessita de desenvolvimento e revisão à medida que as condições históricas mudam" (Ibid.: 6).

A adesão dos intelectuais críticos ao marxismo é compreendida por Kellner como uma reação ao período de violência e desilusão que marcou o início do século XX. A Primeira Guerra Mundial, a Revolução Russa de 1917 e a Revolução Alemã de 1918, acrescidas ao declínio da sociedade burguesa, levaram à união de jovens que passaram a ter - pela primeira vez - contato com o marxismo dentro das universidades. 
Os indivíduos que produziram a teoria crítica conceberam, assim, o marxismo como uma teoria dialética, histórica e em aberto, que exigia desenvolvimento, revisão e modificação, justamente porque era, segundo eles, uma teoria da realidade sócio-histórica contemporânea, que estava constantemente em desenvolvimento e em mudança. (Ibid.: 11)

Ao passo que interpreta os estágios iniciais da tradição crítica como uma "extensão da crítica marxista da economia política para o desenvolvimento de uma teoria abrangente da sociedade" (Ibid.: 53), Kellner reconhece que o marxismo clássico tende "a dar ênfase à primazia da economia e da política, e não dar atenção à cultura e à ideologia" (Id., 2001: 78).

Ele compreende que os teóricos críticos aceitaram a tese de Marx que trata a economia como o fator determinante de toda a estrutura social. No entanto, para Kellner (1984: 119), nenhum deles pode ser interpretado como um reducionista econômico, pois ao contrário destes, os críticos buscaram "descrever o conjunto complexo de mediações que ligam a economia, as instituições sociais e políticas, a cultura e a consciência como partes de uma totalidade social interagindo reciprocamente".

Apesar da tendência marxista, Kellner (1989: 8) argumenta que "não se pode discutir adequadamente a economia sem considerar o papel da política e da cultura na constituição da economia". Avalia ainda que um dos passos mais significativos na trajetória da teoria crítica foi abandonar o "projeto de produzir uma teoria social multidisciplinar enraizada na crítica marxista, da economia política, à de uma nova crítica filosófica da ciência, da tecnologia e da razão instrumental" (Ibid.: 83).

${ }^{1} \mathrm{~A}$ ascensão do nazismo na Alemanha e a integração do mercado de trabalho nos países democráticos foram fatores determinantes para que Adorno e Horkheimer deixassem de enxergar, gradativamente, potencial revolucionário na classe trabalhadora. Durante os anos 1940, percebemse dois movimentos realizados pela tradição crítica: 1) ela se torna mais teórica e elaborada, e 2) se distancia da pesquisa empírica, legado deixado por Carl Grünberg, primeiro diretor do Instituto de Pesquisa Social. O período marca o segundo estágio da teoria crítica. Adorno e Horkheimer observam que a razão científica e a tecnologia são "parte integrante dos processos de produção e dominação social existentes e, portanto, devem ser questionadas" (KELLNER, 1989: 86). Na análise de Kellner (1989: 100), a condução de Adorno e Horkheimer é problemática, pois, entre outras falhas, eles "parecem assumir que toda a ciência e a razão estão ligadas à dominação da natureza e, portanto, estão intrinsecamente ligadas à dominação". Kellner (2009: 6) também compreende que a teoria crítica possui a tendência de pensar que a "cultura midiática simplesmente reproduzia a sociedade existente e manipulava as massas obedientes".
Verificamos, a partir dos anos 1930, determinado desencantamento e, consequentemente, o abandono do marxismo por parte da direção do Instituto. Prova disso, "em 1932, o Instituto parou de publicar a revista Arquivos para a História do Socialismo e do Movimento Operário e criou uma nova revista" (ANDERSON, 1989: 52), chamada Revista de Pesquisa Social.

Para Kellner (1989: 65), a "ausência de um proletariado revolucionário e de uma alternativa socialista emancipatória ao capitalismo de Estado e ao fascismo" levou os intelectuais a questionarem quais eram as reais contribuições que uma defesa da política marxista poderia fornecer, naquela altura, para o desenvolvimento da tradição crítica. O autor chama a atenção, negativamente, para o caso de Horkheimer, que se afastou do marxismo e se aproximou do que Kellner (1990: 14) descreveu como uma "forma de irracionalismo místico derivado de Schopenhauer e Nietzsche". Por outro lado, Marcuse deu continuidade a ensaios com ascendência na dialética marxista ${ }^{1}$.

Dando mérito a Adorno e Horkheimer, o autor indica que o segundo estágio da teoria crítica apresenta, de modo inédito, o desenvolvimento de uma crítica cultural e ideológica sobre a sociedade da era tecnocapitalista. Daí o surgimento do termo indústria cultural. Eles enxergaram a cultura da sociedade "como uma cultura administrada, imposta de cima, como instrumento de doutrinação e controle social" (Id., 1989: 130).

Em uma análise atenta, Kellner revela uma certa ironia dialética presente na escolha do termo indústria cultural. Diferentemente de conceitos como cultura popular ou cultura de massa, a utilização desse termo por Adorno e Horkheimer indica que não estão tratando de produtos culturais de massa porque esses não são produzidos pelas massas, e sim pela indústria cultural.

A cultura, tradicionalmente valorizada, é supostamente oposta à indústria e expressa a criatividade individual, ao mesmo tempo que fornece um repositório de valores humanizadores. Nas indústrias culturais, em contraste, a cultura passou a funcionar como um modo de dominação ideológica, e não como humanizadora ou emancipatória. (Ibid.: 130-131) 
Devemos atribuir grande importância ao período de exílio nos Estados Unidos, uma vez que colaborou para a elaboração do conceito de indústria cultural. Adorno e Horkheimer se confrontaram com uma sociedade que experimentava novas formas de mercantilização dos bens culturais. "Ao contrário da maioria dos habitantes dos Estados Unidos, eles foram capazes de perceber nitidamente até que ponto as indústrias culturais estavam funcionando como instrumentos de controle social e dominação" (Ibid.: 82).

Para além do marxismo tradicional, a teoria crítica argumentou que os indivíduos também foram reificados no processo de consumo, através da visualização passiva de espetáculos de mídia ou tentativas de comprar a felicidade ou resolver problemas através de bens de consumo. A cultura de massa era, portanto, parte integrante da sociedade de consumo, que o Instituto descreveu como uma nova configuração da modernidade capitalista. (Ibid.: 146)

Os pesquisadores observaram as consequências do capitalismo avançado na sociedade norte-americana. A criação de uma "nova ordem social" (Ibid.: 82) via intensificação do consumo, uso da tecnologia, triunfo dos meios de comunicação, domínio científico, além da integração do Estado e da economia. "Nas novas configurações do capitalismo, tudo - bens e serviços, arte, política e vida humana - tornou-se uma mercadoria, enquanto o intercâmbio de commodities se tornou a forma básica de relacionamento na sociedade de consumo" (Ibid.: 147). A teoria crítica encontra no tecnocapitalismo uma "sociedade totalmente administrada, marcada por um declínio da democracia e da individualidade" (Ibid.: 82).

Na interpretação de Kellner (1989: 98), “Horkheimer e Adorno sugerem que o pensamento iluminista deixa, naturalmente, de ser um instrumento para o domínio da natureza, para se tornar um instrumento para a dominação dos seres humanos".

Em Critical theory, marxism, and modernity (1989), nota-se a tentativa de Kellner de estruturar a história do Instituto a partir de pelo menos sete etapas: 1) sob a direção Carl Grünberg, investe-se em estudos empíricos; 2) sob a direção de Horkheimer, nos anos 1930, busca-se uma teoria social com forte influência na obra de Marx; 3) durante o período do exílio, ocorre a dispersão dos membros do Instituto; 4) Adorno e Horkheimer desenvolvem a teoria crítica nos anos seguintes; 5) retorno do Instituto à Alemanha nos anos 1950 e 1960; 6) Marcuse permanece nos Estados Unidos e dá continuidade ao seu trabalho; 7) Habermas retoma os trabalhos do Instituto nos anos 1970 e 1980 . Kellner lembra:

Em 1964, fortemente apoiado por Adorno, Habermas voltou a Frankfurt para assumir a cadeira de Horkheimer em filosofia e sociologia; assim, Adorno foi finalmente capaz de realizar uma sucessão legítima à pessoa que ele pensava ser o mais merecedor e capacitado teórico crítico. (Id., 1984: 207)

O autor avalia que, embora frágil em muitos aspectos, a crítica cultural de Adorno é um dos seus principais legados para o campo de estudo da sociedade e da cultura modernas. Além da primeira teoria neomarxista, Adorno produziu uma crítica da sociedade de consumo. Nela, "a cultura e a estética se misturam com a produção e a publicidade para criar um modo de vida focado no consumo de bens, serviços, imagens de massa e espetáculos" (Id., 1989: 146).

Kellner alerta para a falha que a teoria de Adorno produziu consequentemente, uma vez que na visão neomarxista, "todas as mercadorias são instrumentos uniformemente sedutores da manipulação capitalista, que engendram necessidades falsas homogêneas e falsas consciências" (Ibid.: 158). Isso pressupõe, segundo Kellner (1989: 159), que "se os indivíduos se submetem ao (mau) consumo, são fracos, maleáveis e deficientes como seres humanos - precisamente a atitude puritana em relação ao sexo e ao prazer".

Embora não seja explícita, a teoria de Adorno propõe que o consumo de forma geral, das necessidades às mercadorias produzidas por essa indústria, tem como 
único objetivo escravizar o indivíduo. Pensar apenas nessa perspectiva teórica parece um erro para Kellner.

Enquanto os teóricos críticos tendem a criticar o consumo por ele mesmo como atividade fetichista e mercadorias como intrinsecamente sedutoras e manipuladoras, investigações mais diferenciadas de vários tipos de consumo revelam uma grande variedade de usos de commodities, atitudes em relação a elas e práticas de consumo individualizadas. Muitas pessoas são bastante inventivas e criativas em suas atividades de consumo, e podem crescer e desenvolver-se como seres humanos através do consumo. [...] O consumo pode, portanto, ser uma atividade racional, que melhora a vida, que aumenta os poderes humanos e atende reais necessidades humanas. Consequentemente, em vez de denunciar as commodities e o consumo por ele mesmo, devemos tentar discriminar entre mercadorias valiosas e sem valor ou duvidosas, e consumo desumanizado e "fetichizado" em oposição ao consumo criativo e que melhora a vida (Ibid.: 161).

O autor também argumenta que o modelo teórico de Adorno acerca da indústria cultural "não permite a heterogeneidade da cultura popular e efeitos contraditórios" (Ibid.: 143). Na leitura de Kellner, a cultura popular é reduzida por Adorno sempre à mercantilização, o que significa um "sinal do triunfo total do capital e da reificação total da experiência" (Ibid.).

Kellner entende que, ao examinar o conteúdo da televisão e das músicas populares, Adorno tem uma tendência de apenas "apontar suas ideologias e efeitos 'retrógrados' sobre a consciência, sem analisar suas contradições, momentos críticos ou de oposição, ou potencial para fornecer ideias sobre as condições sociais ou para chegar a uma réplica crítica" (Ibid.: 142).

O filósofo norte-americano reconhece que parte considerável da cultura popular se encaixa no modelo de crítica cultural elaborado por Adorno, mas acredita que "outros exemplos resistam a suas categorias e exigem uma abordagem mais matizada da interpretação e crítica cultural" (Ibid.: 143). Mesmo sem uma argumentação esclarecedora, Kellner considera que o rock e o reggae são exemplos de produções culturais que, muitas vezes, fogem da lógica descrita por Adorno.

Para corrigir a falha no modelo clássico de crítica cultural, Kellner (2009: 6-7) sugere "análises mais concretas e empíricas da economia política dos meios de comunicação e dos processos de produção cultural [...] e estudos de recepção da audiência e dos efeitos da mídia".

O autor considera que Adorno teve seu período mais produtivo a partir dos anos 1950, diferentemente de Horkheimer que, no período, "quase não fez nenhuma contribuição" (Id., 1989: 113). Além de Adorno, o autor destaca a colaboração de Marcuse nos anos 1960. Na época, ele "foi mais amplamente discutido do que qualquer outro filósofo vivo" (Id., 1984: 1). Suas maiores contribuições estão na crítica à sociedade industrial avançada e no pensamento revolucionário.

Ao contrário de Adorno, Marcuse não previu os ataques pós-modernos à razão e ao iluminismo e sua dialética não era "negativa". Em vez disso, Marcuse adotava o projeto de reconstruir a razão e de postular alternativas utópicas à sociedade existente - uma imaginação dialética que foi relegada em uma era que rejeita o pensamento revolucionário e visões grandiosas de libertação e reconstrução social. (Id., 1999a: 17)

Nessa direção, Kellner considera que Marcuse é capaz de fornecer perspectivas filosóficas mais abrangentes sobre os processos de dominação e os caminhos de libertação. O autor destaca a ideia de "desenvolvimento pleno do indivíduo em uma sociedade não repressiva" (Id., 1998: 5) e acredita que a obra de Marcuse apresenta uma "visão de libertação mais rica do que o marxismo clássico, de outras versões da teoria crítica e de versões recentes da teoria pós-moderna" (Ibid.). 
Ao se confrontar com os problemas teóricos e políticos levantados pela modernidade, Kellner encontra em Marcuse recursos importantes para compreender a realidade, apostando que um "renascimento de Marcuse poderia ajudar a inspirar novas teorias e políticas para a era contemporânea, proporcionando à filosofia continental novos impulsos e tarefas" (Ibid.: 7).

Acreditamos que, em síntese, o mérito que Kellner atribui a Marcuse está na forma com que ele compreende o processo de dominação. No capitalismo avançado, a dominação se dá na combinação de economia, política, tecnologia e organização social.

Para os marxistas ortodoxos, o domínio está inscrito nas relações de produção capitalistas e na lógica da mercantilização, e para heideggerianos, weberianos e outros é a tecnologia, a racionalidade tecnológica e/ou a lógica coercitiva das instituições políticas que são a principal força da dominação social. Marcuse, ao contrário, teve uma análise multicausal que afastou aspectos de dominação e resistência em toda a ordem social. Além disso, Marcuse insistiu que as contradições do sistema, teorizadas pelo marxismo clássico como o antagonismo do capital e do trabalho, continuaram a existir, embora em formas alteradas. (Id., 2005: 4)

\section{Estudos de crítica da mídia}

Ao longo dos anos, Kellner se dedicou a trabalhar com as ideias marcuseanas no campo da comunicação. Assim como o estudioso frankfurtiano, ele entende que a mídia e as indústrias de entretenimento "controlam diretamente o tempo livre" (Id., 1984: 170), uma vez que socializam o indivíduo com o objetivo de fazê-lo aceitar as instituições, a ideologia dominante e um modo de vida que não deve ser aceito. Isto é, Marcuse observa que a cultura midiática tem a função de "reduzir indivíduos à passividade cativa e doutriná-los com a ideologia dominante" (Ibid.). Em sintonia com o pensamento do companheiro espiritual, Kellner acrescenta:

Embora as novas formas da indústria cultural [...] - constituídas por cinema, rádio, revistas, histórias em quadrinhos, propaganda e imprensa - tenham começado a colonizar o lazer e a ocupar o centro do sistema de cultura e comunicação nos Estados Unidos e em outras democracias capitalistas, foi só com o advento da televisão, no pós-guerra, que a mídia se transformou em força dominante na cultura, na socialização, na política e na vida social. (Id., 2001: 26)

O levantamento realizado por Kellner acentua a importância, na atualidade, do legado construído pelos pensadores da tradição crítica. Por meio de seus estudos, podemos desenvolver hoje análises críticas com maior profundidade em torno da cultura da mídia, o que pode ser benéfico, em especial, para o campo interdisciplinar da comunicação. O trabalho de Marcuse e de seus colegas mostra a "necessidade de combinar história, teoria social, economia política e estudos de mídia/cultura para adequadamente contextualizar, analisar, interpretar e criticar" (Id., 2009: 3) a cultura produzida pela mídia - e pelo público. Essas reflexões foram determinantes na construção da trajetória conceitual de inúmeros pesquisadores contemporâneos que atuam no campo da comunicação, como é o caso do próprio Kellner.

Embora a julgue teoricamente "parcial e unilateral", Kellner mostra ao longo de seus estudos que a "abordagem da Escola de Frankfurt fornece instrumento para criticar as formas ideológicas e aviltadas da cultura da mídia" (Id., 2001: 45-46). De acordo com sua visão, o Instituto é parcialidade e unilateralidade, por exemplo, quando emprega o conceito de alta cultura. Kellner sinaliza a tendência de definir como alta cultura os bens que apresentam características progressistas, atribuindo-lhes um status de arte autêntica, ao passo que aos produtos tidos como pertencentes à cultura de massa, atribui-se valores negativos, ligados à ideologia dominadora.

O autor entende que o ideal de arte autêntica "limita os momentos críticos, subversivos e emancipatórios a certas produções privilegiadas da cultura 
superior" (Id., 2009: 7). Por isso, a separação entre alta e baixa cultura é um ponto a ser superado e substituído "por um modelo que tome a cultura como um espectro e aplique semelhantes métodos críticos a todas produções culturais que vão desde a ópera até a música popular, desde a literatura modernista até as novelas" (Id., 2001: 45).

Kellner também questiona a posição defendida pelos frankfurtianos de que todos os produtos de massa são aceitos e consumidos sem resistência e de modo uniforme por uma massa passiva de consumidores. $O$ autor defende a necessidade de análises mais profundas, para que os estudos não atribuam aspectos emancipatórios apenas a uma cultura dita como superior, o que reproduz uma visão simplista e limitada de outras produções culturais.

Ele propõe uma "focagem crítica da cultura da mídia, a partir das perspectivas de mercadorização, reificação, ideologia e dominação" (Ibid.), para buscar um "modelo útil para corrigir as abordagens mais populistas e acríticas à cultura da mídia que tendem a subjugar os pontos de vista críticos" (Ibid.: 46).

Desde os anos 1990, Kellner voltou seus estudos para a compreensão das implicações dos meios de comunicação na cultura da sociedade contemporânea. Na sua visão, a cultura da mídia vem se transformando em mais um motor para a economia, na medida em que promove a publicidade de visões de mundo que alimentam o consumo. Aí reside uma das importâncias de estudá-la.

Somando-se a isso, podemos observar a influência que a mídia possui em outras esferas, além da econômica. Na política, Kellner se propõe a analisar as funções exercidas pelos meios de comunicação em guerras e eleições presidenciais que ocorreram nos últimos anos nos Estados Unidos - e sua intervenção em tais eventos, a exemplo da Guerra no Golfo.

Ao estudar a cultura da mídia, Kellner está contribuindo para a tradição crítica, ao mesmo tempo em que atualiza e desconstrói algumas das ideias elaboradas pelos pensadores frankfurtianos.

\section{Referências}

ANDERSON, P. Considerações sobre o marxismo ocidental. São Paulo: Brasiliense, 1989.

KELLNER, D. Herbert Marcuse and the crisis of marxism. Berkeley: University of California Press, 1984.

. Critical theory, marxism, and modernity. Cambridge: Polity Press, 1989.

. Critical theory and the crisis of social theory. UCLA Graduate School of Education \& Information Studies, Los Angeles, 1990. Disponível em: <https://goo. gl/R3Psc7>. Acesso em: 8 jul. 2017.

. O Marcuse desconhecido: novas descobertas nos arquivos. In: MARCUSE, H.; KELLNER, D. (Eds.). Tecnologia, Guerra e Fascismo. São Paulo: Fundação Editora da Unesp, 1999a.

. Hebert Marcuse. UCLA Graduate School of Education \& Information Studies, Los Angeles, 1998. Disponível em: <https://goo.gl/tvDcFN>. Acesso em: 8 jul. 2017.

A cultura da mídia-Estudos culturais: identidade e política entre o moderno e o pós-moderno. Bauru: EDUSC, 2001.

. Adventures in Continental Philosophy. UCLA Graduate School of Education \& Information Studies, Los Angeles, 1999b. <https://bit.ly/2GbnMIL>. Acesso em: 3 jul. 2017. 
The new left and the 1960s. UCLA Graduate School of Education \& Information Studies, Los Angeles, 2005. Disponível em: <https://goo.gl/bm2d61>. Acesso em: 8 jul. 2017.

Political economy and cultural studies. UCLA Graduate School of Education \& Information Studies, Los Angeles, 2009. Disponível em: <https://goo.gl/9Jiemg>. Acesso em: 8 jul. 2017. 